\title{
O EFEITO METAFÓRICO NA AAD-69: UM GESTO DE LEITURA MEDIADO NO DIÁLOGO COM OS ESCRITOS DE LINGUÍSTICA GERAL
}

\section{THE METAPHORICAL EFFECT IN ADA69: A MEDIATED READING STANCE IN DIALOGUE WITH WRITINGS IN GENERAL LINGUISTICS}

\author{
Júlio César dos Reis Petter* \\ UFRGS \\ Clara Állyegra Lyra Petter** \\ PUCRS \\ Luciene Jung de Campos*** \\ UCS
}

\begin{abstract}
Resumo: Propõe-se uma leitura crítica comparada do conceito de efeito metafórico de Pêcheux (1969) com parte da bibliografia de Saussure: Curso de Linguística Geral (CLG) e Escritos de Linguística Geral. Com a publicação do CLG (SAUSSURE, 1916), o pensamento saussuriano consolidou uma ruptura paradigmática no fazer das ciências humanas. Mais do que influenciar, essa revolução foi base epistemológica e ponto de diferenciação para o florescimento de diversas correntes teóricas. A Análise de Discurso, fundada por Pêcheux, aparece como área de entremeio entre a linguística saussuriana, o materialismo histórico e a psicanálise. Análise Automática do Discurso (1969) é a obra seminal do campo, definindo o panorama teórico no qual se forja o efeito metafórico, mecanismo pelo qual uma substituição de termos mantém o efeito de sentido no fio do discurso. Delineamos com estado de língua o ponto de ancoragem para que relações sintagmáticas e associativas fossem lidas no funcionamento do efeito metafórico, estabelecendo condições para abordarmos a evolução da língua discursivamente com os compromissos do espírito e a analogia. Na esteira do interesse renovado pela AAD-69, objetivou-se proporcionar aos analistas do discurso uma leitura do conceito de efeito metafórico à luz de uma interlocução que resgatasse preceitos basilares da linguística saussuriana.
\end{abstract}

Palavras-Chave: Efeito metafórico. Análise de discurso. Linguística saussuriana.

\begin{abstract}
We propose a critical comparative analysis between the concept of Metaphorical Effect as defined by Pêcheux in 1969 and some concepts in the works of Saussure: Course in General Linguistics and Writings in General Linguistics. The publication of Course in General Linguistics in 1916 caused a widespread rupture in the methods and epistemology of Human Sciences. Not a mere influence, Saussurean linguistics brought a paradigmatic rupture that paved the way for the development of many theories. French Discourse Analysis, proposed by Michel Pêcheux, arises as an in-between area of Saussurean

\footnotetext{
* Mestrando em Letras - Estudos da Linguagem pela Universidade Federal do Rio Grande do Sul. E-mail: juliopetter@outlook.com.br.

** Especialista em Estudos de Tradução pela Pontifícia Universidade Católica do Rio Grande do Sul. E-mail: ally.gra@gmail.com.

*** Doutora em Letras - Estudos da Linguagem Pela Universidade Federal do Rio Grande do Sul. E-mail: ljungdecampos@gmail.com.
} 
linguistics, Historical Materialism, and Psychoanalysis. Pêcheux’s Automatic Discourse Analysis is the groundwork of this area and defines its fundamental theoretical framework, where he developed the Metaphorical Effect: a mechanism through which it is possible to replace words and yet maintain the discourse's semantic effects. Evoking the concept of Language State as an anchoring point, we could look into Syntagmatic and Associative Relations functioning alongside the Metaphorical Effect, thus, establishing conditions to approach discursively the evolution of language in relation with the commitments of the mind and the Analogy. With a renewed interest of the academic community in the ADA69, we aim to bring for these analysts a deeper understanding of the Metaphorical Effect through reexamining key concepts in Saussurean Linguistics.

Keywords: Metaphorical Effect. French Discourse Analysis. Saussurean Linguistics.

\section{CONSIDERAÇÕES INICIAIS}

O produto do esforço empreendido em 1916 por Charles Bally e Albert Sechehaye para a organização e publicação do Curso de Linguística Geral (1975; doravante CLG), posteriormente conhecido como vulgata dentro dos estudos saussurianos, surge como uma ruptura paradigmática nas ditas ciências humanas. Arrivé (2007, p. 22-23) afirma que foi por meio da vulgata que “o pensamento de Saussure exerceu sua influência sobre a evolução da linguística e das ciências humanas do século XX”, sendo o único texto lido entre 1915 e 1957 para compreender a linguística saussuriana. Com as fortes reverberações do CLG, linguistas, antropólogos, historiadores, sociólogos, dentre outros pesquisadores, tiveram tanto a relação com as práticas do seu fazer quanto a própria forma de delinear seu objeto irremediavelmente transformadas. A herança saussuriana é de tal impacto e amplitude que reflete a ousadia de seu mestre. Uma amostra da radicalidade da intervenção que propunha Ferdinand de Saussure já pode ser encontrada no escrito, datado de 1891, acerca da primeira conferência na Universidade de Genebra, no qual ele provoca a reflexão sobre o papel do estudo da linguagem ao questionar:

vocês pensam seriamente que o estudo da linguagem teria necessidade, para se justificar ou para se desculpar por existir, de provar que é útil às outras ciências? [...] A que ciência se pede, como condição preliminar para existir, que se empenhe em fornecer resultados destinados a enriquecer as outras ciências que se ocupam de outros objetos? Isso é recusar a ela qualquer objeto próprio (SAUSSURE, 2004, p. 127).

Vemos aqui uma das primeiras evidências públicas e registradas desta crítica pungente que o autor fazia ao trabalho científico de sua época. A linguística se tornou a ciência modelo das humanidades por excelência, influenciando muitos dos pensadores subsequentes a desenvolverem suas práticas seja em consonância seja em divergência com ela, adotando-a como ponto de partida teórico, metodológico ou mesmo epistemológico. Os estudos conduzidos por Jakobson (na disseminação da Linguística Estrutural e elaboração de sua Teoria da Comunicação) e por Lévi-Strauss (fundador da Antropologia Estrutural) são alguns dos trabalhos notáveis nas ciências humanas com base ou inspiração nesse movimento. Nessa linha, ao comentar sobre a influência de Saussure sobre teóricos da linguística e das ciências humanas no século XX, Arrivé (2007) afirma: 
Para citar, em desordem, apenas os nomes evocados acima, Meillet, Trubetzkoy, Hjelmslev e Merleay-Ponty só conheceram o Curso por meio da "vulgata". Jakobson, Benveniste, Martinet, Lacan, Lévi-Strauss, Barthes e Greimas tiveram conhecimento, em graus diversos, da existência das fontes manuscritas e de suas divergências com o texto padrão. Mas, essencialmente, foi a "vulgata” que deu forma a sua reflexão. (ARRIVÉ, 2007, p. 23, grifos do autor)

Dentre as várias disciplinas fundadas na esteira da ruptura saussuriana, destacamos a Análise de Discurso (AD) fundada por Michel Pêcheux, também reconhecida hoje como Análise de Discurso Materialista. Ressaltamos nossa tomada de posição política ao aderirmos ao movimento que emprega a formulação Análise de Discurso Materialista para demarcar firmemente nossa vinculação e identificação com os textos clássicos da área inaugurada por Michel Pêcheux e seus pressupostos. Diz-se Materialista na acepção do delineamento proposto por Althusser na leitura das obras de Karl Marx, sendo, de forma simplificada, a "teoria das formações sociais e de suas transformações, compreendida aí a teoria das ideologias” (PÊCHEUX; FUCHS, 2014, p. 160). Essa demarcação tem estatuto preciso e designa um movimento de resgate frente às derivas teóricas e institucionais que tem ocorrido na institucionalização da AD no Brasil.

AAD se origina nas teses desenvolvidas por Michel Pêcheux na França, a partir de 1966, ao articular três áreas distintas do conhecimento: o materialismo histórico, a linguística e a teoria do discurso, atravessadas por uma teoria psicanalítica do sujeito (PÊCHEUX; FUCHS, 2014, p. 160). Afirma-se que Pêcheux foi um leitor atento da obra de Saussure, tendo não somente estudado a fundo a vulgata, como também as Sources manuscrites du CLG, as publicações de Starobinski e o trabalho sobre os Nibelungen (GADET et al., 2014, p. 40-42). Além disso, na elaboração de suas propostas, Pêcheux teve, como forte referência, outros autores notadamente influenciados por Saussure, como Jakobson, Benveniste e Lacan. Dessa forma, ao considerarmos os efeitos da influência linguística em AD, não se fala de qualquer linguística, mas do legado saussuriano em suas minúcias.

A Análise Automática do Discurso (2019; doravante AAD-69), livro datado de 1969, é a obra seminal de Pêcheux na $\mathrm{AD}$. Logo nas primeiras páginas de seu texto, o autor cita nominalmente a importância do $C L G$ e do deslocamento saussuriano nos estudos da linguística e do texto:

ora, o deslocamento conceitual introduzido por Saussure consiste precisamente em separar essa homogeneidade cúmplice entre a prática e a teoria da linguagem: a partir do momento em que a língua deve ser pensada como um sistema, deixa de ser compreendida como tendo a função de exprimir sentido; ela se torna um objeto do qual uma ciência pode descrever funcionamento (PÊCHEUX, 2019, p. 18 , grifos do autor).

A partir desse deslocamento, uma teoria da linguagem que pode ter seu funcionamento analisado e descrito, Pêcheux aponta em seus trabalhos para um espaço abandonado pela trajetória do cientificismo corrente na linguística de seu tempo. Ele vai se propor a trabalhar "no terreno deixado livre pela linguística”, visando examinar diferentes tipos de respostas a questionamentos como “o que quer dizer este texto?” e “que significação contém esse texto?” (PÊCHEUX, 2019, p. 19). Pode-se notar que, desde os primórdios da AD, a linguística saussuriana é parte do 
panorama epistemológico irredutível e, ao mesmo tempo, é ponto de inflexão necessário para o desenvolvimento da teoria do discurso (PÊCHEUX; FUCHS, 2014, p. 159-160).

Cabe aqui uma observação importante: é pacificado na AD seu estatuto como disciplina situada no entremeio conflituoso da tensão dos três campos que a constituem. Assim, ela não se constitui como uma colagem multidisciplinar das características chave dessas áreas. Dessa forma, podemos estender com tranquilidade o entendimento apresentado anteriormente acerca da linguística saussuriana para a psicanálise e o materialismo histórico, no entanto esses não são o foco e escopo deste trabalho.

Antes de prosseguirmos, faremos algumas ponderações sobre as opções teóricas, bem como sobre os nossos limites neste exercício de leitura mediada. Partimos do lançamento de uma nova edição da $A A D$-69 no IX Seminário de Estudos em Análise do Discurso (SEAD 2019), o qual reacendeu a centelha do interesse da comunidade acadêmica nessa época da AD, a dita maquinaria discursivo-estrutural do período até 1975, resultando em tentativas de recontextualização de conceitos e abordagens. O efeito metafórico é um desses conceitos parcialmente relegados no período pós-maquinaria discursiva, pois, quando o processo de produção discursiva deixa de ser visto como fechado e autodeterminado em si mesmo, a ideia de estabilidade que permitia a justaposição das unidades é parcialmente desmontada. Como parte integrante da lógica de software concebida por Pêcheux, com o fim do analisador automático, as minúcias operacionais do conceito foram esvaziadas, sobrevivendo hoje, à comunidade acadêmica, somente na forma de uma construção vaga. Atermo-nos ao período da $A A D 69$ nessa leitura mediada é um esforço tanto para nos inserirmos no movimento global de retomada desta, quanto para evitarmos a homogeneização decorrente de seu apagamento no passar dos anos.

Sob o risco de incidirmos neste artigo tanto em anacronismo quanto em projeção, também é imprescindível reiterarmos que não pretendemos, em momento algum, rastrear os percursos ou definir origens para qualquer construção. Os escritos foram descobertos apenas em 1996, de forma que não é possível legitimar qualquer posição teórico-metodológica de Pêcheux a partir de enunciados que ele nunca leu. Procuramos, neste artigo, tão somente efetuar uma justaposição crítica de partes da obra de Ferdinand de Saussure com a $A A D-69$, de Michel Pêcheux, num gesto de leitura mediado. Neste esforço, buscou-se sobretudo estabelecer um diálogo direto entre o "efeito metafórico" desenvolvido por Pêcheux e noções centrais em Saussure, como analogia e relações sintagmáticas e associativas, de forma a contribuirmos com os esforços de recontextualização dos conceitos e abordagens da $A A D-69$.

Para além do diálogo direto, é imprescindível advertir ao leitor sobre a recorrente presença transversal de conceitos, por exemplo, o valor linguístico, os estados de língua, dentre tantos outros. Reconhecemos o estatuto e o lugar precisos dos conceitos saussurianos, porém, mesmo que haja uma tentativa de delimitação do escopo, a organização da linguística saussuriana se estrutura firmemente em forma de uma rede complexa de relações interdependentes. No sistema saussuriano, a própria existência desses estatutos só pode ser concebida como o é, devido a esse imbricamento de colaboração mútua, em outras palavras, uma orquestra bem arranjada na qual cada verdade individualmente carrega em seu âmago toda a essência do pensamento saussuriano, pois: 
parece impossível, de fato, dar preeminência a tal ou tal verdade da linguística, de maneira a fazer dela o ponto de partida central: mas há cinco ou seis verdades fundamentais tão ligadas entre si que se pode partir indiferentemente de uma ou de outra que se chegará logicamente a todas as outras e à mais ínfima ramificação das mesmas consequências, partindo de qualquer uma dentre elas (SAUSSURE, 2004, p. 23).

Tendo em vista a abrangência e a dispersão que a recepção das ideias de Saussure teve, e ainda tem, nas ciências humanas, conceber a influência de seu pensamento em autores posteriores se mostra uma tarefa de difícil execução. Dito isso, não se faz necessário limitarmo-nos àquilo que sabemos por meio de registros formais que um autor leu sobre o outro. Adotar essa limitação seria uma postura potencialmente equivocada e essencialmente redutora, pois nela se negligencia a rápida troca de conhecimentos e a atividade pulsante nas comunidades científicas, nos grupos acadêmicos e a fluida circulação de ideias que ocorria com vigor na primeira metade do século XX (KUHN, 2013). Especialmente quando se considera o caso de Ferdinand de Saussure e sua linguística, muito pouco de sua produção foi formalmente registrada. Não é a vulgata de 1916 (ou as edições comentadas), nem sua pequena bibliografia autográfica, tampouco os materiais achados posteriormente, que necessariamente refletem integralmente o pensamento do linguista. É devido à existência desse todo já-dito circulante do pensamento linguístico - ou seja, o fluxo de desenvolvimento dos paradigmas científicos, como desenvolvido por Kuhn (2013) - nessa temporalidade histórica do início do século XX que permite a instauração de desenvolvimentos paradigmáticos decorrentes, como: a edição do CLG por Charles Bally e Albert Sechehaye; os desdobramentos e proposições estruturalistas; as contribuições psicanalíticas no campo da linguagem; e a teoria de Michel Pêcheux. Inseridos neste panorama, concordamos e seguimos os questionamentos de Arrivé (2010) sobre como considerar a obra de Saussure:

é preciso levar em conta estritamente a versão padrão? Isso seria ficar cego diante de certos aspectos decisivos, apesar de seu relativo ocultamento, do pensamento de Saussure. Ou seria indispensável recorrer exclusivamente às fontes manuscritas? Isso seria, então, impedir-se de entender alguns aspectos da influência exercida pelo Curso. Não seria preferível levar em consideração, ao mesmo tempo, as duas tradições, não sem antes distingui-las com o máximo de rigor? (ARRIVÉ, 2010, p. 26, grifo do autor).

Ao se retornar aos clássicos e explorar as premissas teóricas basilares tanto em Ferdinand de Saussure quanto em Michel Pêcheux, arranja-se um movimento com propósito primordial de proporcionar uma compreensão expandida, mas ainda assim firmemente fundamentada do efeito metafórico à comunidade acadêmica da AD. Iniciaremos abaixo este que é um gesto de leitura mediado pelo diálogo íntimo com o material autográfico presente nos Escritos de Linguística Geral (2004) e, no entanto, sem nunca cogitar, como já apontado, renunciar ao CLG e suas numerosas contribuições ao campo. 


\section{ESTADO DE LÍNGUA COMO ANCORAGEM SEMÂNTICA NO JOGO DE DESLIZAMENTOS}

Na formulação e estruturação desse campo singular que é a AD, Pêcheux se preocupa extensivamente com a ideia de fornecer um instrumento científico às ciências sociais. Nos trabalhos assinados em 1967 e 1968 sob o pseudônimo de Thomas Herbert, seu questionamento é centrado numa compreensão singular do estado, dito pré-científico, das ciências sociais e sua apropriação dos instrumentos científicos. Ao criticar duramente a psicologia social, ele lança mão de uma elaborada estratégia para sustentar, numa comunidade acadêmica de inclinação dissonante à sua, a tese de que metáfora e ideologia não são desvios, mas o próprio cerne da produção de sentidos. Na $A A D$-69, há o interesse explícito a respeito das problemáticas ao redor da semântica e da metáfora, tratadas nesse momento por meio da conceituação do efeito metafórico. Este, por sua vez, é peça essencial na maquinaria, pois permitirá "extrair os domínios semânticos” para analisar cada forma discursiva possível (PÊCHEUX, 2019, p. 63, grifo do autor). É somente no concatenamento desses esforços que seria possível delinear uma teoria completa na qual se esboçasse "uma análise não-subjetiva dos efeitos de sentido" (PÊCHEUX; FUCHS, 2014, p. 168) provocados na articulação e no uso dos diferentes discursos.

O efeito metafórico é um dos dispositivos desenvolvidos na trama conceitual interdependente da AD para operar sobre o seguinte enunciado: "sejam dois termos $x$ e $y$, pertencentes a uma mesma categoria gramatical em uma língua dada $\mathcal{L}$. Existe pelo menos, um discurso no interior do qual $x$ e $y$ possam ser substituídos um pelo outro sem mudar a interpretação desse discurso?” (PÊCHEUX, 2019, p. 52, grifos do autor). É definido como “o fenômeno semântico produzido por uma substituição contextual” pelo qual dois grupos de termos ou expressões "produzem o mesmo efeito de sentido em relação a um contexto dado mantendo a relação de sinonímia no discurso" (PÊCHEUX, 2019, p. 54).

Ao escolher prosseguir com a hipótese da substituição contextual - na qual substituições são possíveis somente às vezes - como regra geral, Pêcheux o faz em observância àquilo que considera ser "característico dos sistemas linguísticos “naturais”” (PÊCHEUX, 2019, p. 54, grifo do autor). Assim, molda a teoria ao entender as muitas particularidades e limitações impostas pela fluidez do jogo de negatividades entre os valores no imbricado sistema ordenado dos signos linguísticos. A partir dessa asserção, podemos contribuir para um melhor entendimento, resgatando o questionamento e a subsequente discussão a respeito da natureza do objeto em linguística, elencados pelo próprio Saussure nos Escritos de Linguística Geral (2004):

Será que a lingüística encontra diante de si, como objeto primeiro e imediato, um objeto dado, um conjunto de coisas evidentes [...]? De maneira alguma e em momento algum [...]. Não há nenhuma entidade linguística, que possa ser dada, que seja dada imediatamente pelo sentido; nenhuma que exista fora da idéia que lhe possa ser vinculada; [...] não há nada em comum, em essência, entre um signo e aquilo que ele significa (SAUSSURE, 2004, p. 23).

Nem os objetos, tampouco os sentidos, podem ser dados a priori pois não existe uma amarração que os una de forma unívoca na natureza: é necessário que haja a vinculação dos significados e significantes, respeitando as relações vigentes do sistema dado, num momento específico. A própria significação é "apenas uma maneira de exprimir o valor de uma forma" 
(SAUSSURE, 2004, p. 41), evidenciando o status secundário do sentido frente à constituição do sistema e suas relações. Há respaldo para essa constatação em Saussure ao expor que “o sentido pode variar numa medida infinita sem que o sentimento de unidade do signo seja, nem mesmo vagamente, atingido por essas variações” (SAUSSURE, 2004, p. 41). Em outras palavras, o reconhecimento de um estado de língua estabelecido é criado, respeitando o "princípio das OPOSIÇÕES, ou dos VALORES RECÍPROCOS, ou das QUANTIDADES NEGATIVAS e RELATIVAS” (SAUSSURE, 2004, p. 27, grifos do autor), engendrado no sistema de signos da língua.

Entretanto, é essencial reconhecer que, mesmo sem sentidos dados a priori, essas vinculações, ocorridas em dado estado de língua e respeitando as relações de negatividade, não significam que inexiste um ordenamento aceitável dentre o todo possível das relações. Na realidade, encontra-se exatamente o oposto:

de maneira geral, a língua repousa sobre um certo número de diferenças ou de oposições que ela reconhece, sem se preocupar essencialmente com o valor absoluto dos termos opostos, que poderá variar consideravelmente, sem que o estado de língua seja destruído (SAUSSURE, 2004, p. 37).

Por mais que a variação dos valores seja considerável, a própria língua não aceita qualquer diferença: ela impõe um limite das possibilidades reconhecíveis, limite esse que não é dado $a$ priori, só podendo começar a ser delineado após análises. A conformação deste limite existe em um estado de língua, “um espaço de tempo, mais ou menos longo, durante o qual a soma de modificações ocorridas é mínima” (SAUSSURE, 1975, p. 119-120). Ou seja, podemos afirmar que a composição do sistema da língua com um estado bem delimitado das condições de produção é esse estado de língua, no qual é possível colocar em evidência pontos de ancoragem semânticos para o jogo de deslizamentos das metáforas.

\section{RELAÇÕES SINTAGMÁTICAS E ASSOCIATIVAS E AS NECESSIDADES IRREMEDIÁVEIS ÀS SUBSTITUIÇÕES UM A UM}

Consideradas as vastas possibilidades das relações de negatividade do valor em um único estado de língua, é improdutivo buscar qualquer relação de sinonímia que transcenda entre estados diversos, pois desrespeitaria o que vimos anteriormente. Sendo cada estado radicalmente diferente um do outro, não há ponto de ancoragem comum que permita estabelecer algum parâmetro estável para se efetuarem comparações.

É sensato, então, abordar o objeto por outro panorama e tomar por regra geral que a substituição que preserva a interpretação original é uma dentre muitas possibilidades existentes e que, necessariamente, precisa ser comprovada no contexto dado. Pêcheux vai por esse caminho ao reconhecer as impossibilidades trazidas com as noções de vinculação de sentido dependentes de relações negativas, inexistência de significado a priori e impossibilidade de comparação entre estados de língua diversos.

Dessa forma, a existência de efeito metafórico entre termos de discursos diversos requer que eles possuam entre si “interpretação semântica idêntica”. Em outras palavras, para se provar a existência do efeito metafórico, duas necessidades devem ser atendidas: que os lexemas em 
questão possuam “contexto comum de substituição” entre si e que os enunciados que os contêm tenham "posição funcional” similar frente a outro igual número de enunciados com interpretação semântica idêntica já estabelecida (PÊCHEUX, 2019, p. 59). Para ambas as necessidades, todos os discursos mobilizados (e suas respectivas materialidades, os enunciados) precisam partir de um mesmo processo de produção.

Na $A A D-69$, um processo de produção específico necessariamente implica a operação de composição entre as condições de produção e um sistema linguístico dado (PÊCHEUX, 2019, p. 45). Entendem-se condições de produção, conforme a $A A D-69$, como o fenômeno de funcionamento não integralmente linguístico pelo qual há a colocação dos protagonistas e do objeto no discurso (PÊCHEUX, 2019, p. 35). Satisfazemo-nos com essa definição devido ao recorte temporal e escopo material escolhidos para este artigo, bem como não ser nosso foco debater as minúcias das particularidades de outros elementos da rede conceitual da AD. Neste gesto de leitura mediado, a justaposição crítica nos permite deduzir que esse elemento limitador imposto foi projetado para proporcionar um espaço-tempo estável ao analista do discurso para operar com a língua na maquinaria discursiva da $A A D-69$ e tornar o efeito metafórico um constructo possível.

Propomos a exploração do “contexto comum de substituição”, retomando as relações associativas, ou como apresentada nos Escritos de Linguística Geral (2004): a "paralelie ou fala potencial, [...] regime no qual um elemento leva uma existência em meio a outros elementos possíveis” (SAUSSURE, 2004, p. 58, grifo do autor). As relações em paralelie são existências potenciais vinculadas sempre a uma dada presença concreta na língua, possibilidades num dado estado de língua, afinal "um signo em linguagem só existe pelo estrito fato da existência de outros” (SAUSSURE, 2004, p. 47). Pêcheux (2019, p. 55) reconhece essas realidades inescapáveis do signo e conforma sua teoria ao requisito imposto pela linguística saussuriana ao preconizar que qualquer operação de substituição ou equivalência na ordem do discurso deve sempre ser feita termo a termo, um a um, entre o presente e o potencial.

Buscando clarificar o nosso percurso até aqui, resgatemos de forma despretensiosa parte do exemplo de Pêcheux (2019, p. 61) no qual ele propõe a investigação sobre a ocorrência do efeito metafórico estre os termos "raio", “tiro" e "clarão” dentro de um dado sintagma A:

(A1) tiro

(A) (A2) Um clarão atravessou a noite $\uparrow$ raio

O autor nos afirma que essas três possibilidades (a substituição no sintagma entre "raio", “tiro” e “clarão”) preenchem a “condição de proximidade paradigmática”, visto que podem ser substituídas com êxito umas pelas outras nesse contexto comum ("atravessou a noite”), resultando em interpretação semântica idêntica em todas as combinações (A1, A2 e A3). O que permite isso é a relação associativa, já que todo e qualquer "termo dado é como o centro de uma constelação, o ponto para onde convergem outros termos coordenados cuja soma é indefinida” (SAUSSURE, 1975, p. 146). 
A respeito da “posição funcional” dos enunciados nos quais se inserem os termos, complementa Pêcheux (2019, p. 59) que esses lexemas precisam conseguir desempenhar o mesmo papel na estrutura interna dos enunciados com relação ao seu contexto imediato em cada um dos discursos em comparação. Essa restrição evidencia a necessidade de se levar em consideração as relações limitadas de função - internas ao enunciado e relativas à sintaxe -, bem como convoca um diálogo com a noção saussuriana de sintagma, pois segue a mesma forma básica deste: "um sintagma suscita [...] a idéia de uma ordem de sucessão e de um número determinado de elementos” (SAUSSURE, 1975, p. 146).

A função desempenhada decorre da posição do elemento em determinado ordenamento, é o engendramento no conjunto de regras permitidas pela estrutura da língua. Estabelecida a conexão, é possível verificar que as características básicas do sintagma delineiam as formas como posições funcionais semelhantes que podem ser observadas, sendo um retorno às relações de valor decorrentes de oposições: "Colocado num sintagma, um têrmo só adquire seu valor porque se opõe ao que o precede ou ao que o segue, ou a ambos. [...] A relação sintagmática existe in praesentia; repousa em dois ou mais têrmos igualmente presentes numa série efetiva” (SAUSSURE, 1975, p. 142-143, grifo nosso).

Considerando isso e voltando ao exemplo de Pêcheux (2019, p. 61), deve-se notar a dependência da relação entre possibilidades in absentia e sintagma posto, pois, quando incorporamos mais contexto, as relações discursivas se alteram:

(B1) O xerife avançava em direção ao saloon, um clarão atravessou a noite.

(B2) O xerife avançava em direção ao saloon, um tiro atravessou a noite.

Assim, o sintagma B1 poderia ter igual efeito metafórico que o sintagma B2. Porém, aqui a substituição associativa em A3 com “raio” já não possui mais interpretação semântica idêntica. Da mesma forma ocorre com o termo “tiro” de A1, se considerarmos o sintagma:

(C1) A tempestade ribombava, um clarão atravessou a noite.

(C)

(C2) A tempestade ribombava, um raio atravessou a noite.

Disto resulta o efeito metafórico de que “tiro = clarão” em B e que “clarão = raio” em C, mas que só se prova verdadeiro em cruzamentos específicos de relações sintagmáticas e associativas. Disso, Pêcheux (2019, p. 62) nos ensina que "as relações de interpretação semântica não são transitivas", logo dizer que "tiro = clarão" e "clarão = raio" não implica que "tiro = raio”, pois, apesar de cumprida a “condição de proximidade paradigmática”, não está cumprida a “condição de identidade das posições funcionais”. Assim, a interpretação semântica em B é diferente da interpretação semântica em C.

Defendemos a associação direta com as relações em presença organizadas no sintagma quando considerada a atribuição de sentido desses lexemas, pois na "delimitação qualquer de outros termos existentes no mesmo momento [um termo] só assume aquele sentido no enunciado 
específico pela delimitação imposta pela presença dos outros termos concomitantes na relação sintagmática” (SAUSSURE, 2004, p. 70, grifo do autor). Assim como os conceitos saussurianos são mutuamente interdependentes em sua concepção e uso, o mesmo se observa na relação dicotômica constituinte da "interpretação semântica idêntica” necessária ao efeito metafórico.

Ressaltamos o entendimento que a operação de composição presente no processo de produção comum aos discursos em análise fará com que as condições de produção ajam como elemento limitador perante o sistema linguístico. Isso imporá ao analista de discurso a necessidade de corretamente situar as condições de produção em análise em seu trabalho com a língua. A questão da conjuntura e a sua conexão material no espaço-tempo ressoa com a constatação, nos Escritos de Linguística Geral (2004), de que "há, em cada região do globo, um estado de língua que se transforma lentamente” (SAUSSURE, 2004, p. 134), mostrando que esse recorte não é, de forma alguma, descabido e que a relativa estabilidade do estado de língua também supõe um componente tanto geográfico quanto populacional. Desse modo, a operação de composição e a subsequente limitação que se impõe são arquitetadas por Pêcheux (2019) no reconhecimento de que a língua e seus elementos, como preconizados na linguística saussuriana, são indivisíveis e devem sempre ser tomados de empréstimo em sua totalidade.

\section{OS COMPROMISSOS ASSUMIDOS PELO ESPÍRITO E A EVOLUÇÃO DA LÍNGUA ATRAVÉS DA ANALOGIA E DOS ESQUECIMENTOS}

Na relação entre dois discursos oriundos de um mesmo processo de produção, Pêcheux (2019, p. 62) nos adverte que é altamente improvável que o todo ali possível dos efeitos metafóricos seja equivalente, isomorfo. Uma possível intenção do sujeito falante não é um ponto de interesse no panorama epistemológico da $\mathrm{AD}$. De fato, seu objeto se situa nos tensionamentos ocasionados pela sujeição constitutiva do psicológico - o dito espírito - no efeito de transparência presente na própria materialidade linguística em análise. Essa observação nos impõe que resgatemos as noções dos esquecimentos $\mathrm{n}^{\circ} 1$ e $\mathrm{n}^{\circ}$ 2, conforme definido por Pêcheux e Fuchs (2014, p. 176-177), para traçarmos novos diálogos:

na medida em que o sujeito se corrige para explicitar a si próprio o que disse,
para aprofundar 'o que pensa' e formulá-lo mais adequadamente, pode se dizer
que esta zona [esquecimento] $\mathrm{n}^{\circ}$ 2, que é a dos processos de enunciação, se ca-
racteriza por um funcionamento do tipo pré-consciente/consciente. Por oposição,
o esquecimento $\mathrm{n}^{\circ} 1$, cuja zona é inacessível ao sujeito, precisamente por essa
razão, aparece como constitutivo da subjetividade na língua. Desta maneira, pode-
-se adiantar que este recalque [...] é de natureza inconsciente, no sentido em que
a ideologia é constitutivamente inconsciente dela mesma (PÊCHEUX; FUCHS,
2014, p. 176-177).

Ou seja, o esquecimento $\mathrm{n}^{\mathrm{o}} 1$ resulta que o sujeito acredita que tem controle sobre os sentidos que enuncia, e o esquecimento $\mathrm{n}^{\circ} 2$, que ele acredita que é fonte do seu dizer. A sintaxe da língua se impõe ao sujeito, que hesita, cerceia, adjetiva e precisa se corrigir enquanto enuncia para tentar conter deslizamentos próprios da fala (como o chiste e o zeugma). Esses deslizamentos evidenciam, no fio do discurso, aqueles elementos além de seu controle, que são dependentes dessa subjetividade e afetam singularmente o sentido do que está ali dito. É com 
os esquecimentos $n^{\circ} 1$ e $n^{\circ} 2$ que ocorre o processo de composição do sistema linguístico com a Ideologia no qual o discurso adquire forma material. É nesse contínuo jogo de forças entre a língua, a Ideologia e o inconsciente que as relações entre os efeitos metafóricos dentro de um mesmo processo de produção se deformam e escorrem, dando origem, assim, a relações de dominância desiguais para essas metáforas.

Em nosso movimento de justaposição crítica, o prisma dessa mesma confluência pode ser explorado numa posição centrada na língua, nos Escritos de Linguística Geral (2004), quando encontramos que:

a linguagem é, a cada momento de sua existência um produto histórico, isso é evidente. Mas que, em momento algum da linguagem, esse produto histórico representa outra coisa que não seja o último compromisso que o espírito aceita com certos símbolos, eis aí uma verdade mais absoluta ainda, já que sem este último fato não haveria linguagem (SAUSSURE, 2004, p. 180).

Até um novo compromisso ser forjado, um processo de tensão para mudança e evolução vai se formando na figura das analogias: "eu quero lembrar, de dois agentes distintos, um psicológico, que se concentra na 'operação de analogia', o outro mecânico, fisiológico [...]” (SAUSSURE, 2004, p. 144-145). As operações de analogia se encontram na massa de falantes, "esse fenômeno [analogia] representa uma associação de formas no espírito, citada pela associação das ideias representadas” (SAUSSURE, 2004, p. 140, grifos do autor), que dominarão as associações das formas com as ideias, mesmo que cerceadas pelas regras do sistema. A evidência dessa interdependência é resgatável quando se admite que:

uma língua qualquer num momento qualquer nada mais é do que um vasto enredamento de formações analógicas, [...] esses fatos: não são fatos excepcionais ou anedóticos, não são curiosidades ou anomalias, mas a substância mais clara da linguagem, em qualquer parte e em qualquer época (SAUSSURE, 2004, p. 140141, grifos do autor).

Se um estado de língua não é nada além desse “vasto enredamento de formações analógicas” - fruto das associações sancionadas pelo espírito - e está em constante reorganização e evolução - resultando em novos compromissos aceitos com certos símbolos -, é de se questionar: o polimorfismo das relações metafóricas pode ser intencionalmente controlado? Sendo essas relações da ordem do discurso parcialmente linguísticas, pode-se refletir:

os fatos lingüísticos podem ser tidos como resultado de atos de nossa vontade? Tal é, portanto, a questão. A ciência da linguagem, atual, lhe dá uma resposta afirmativa. Só que é preciso acrescentar, imediatamente, que há muitos graus, como sabemos, na vontade consciente ou inconsciente; ora, de todos os atos que se poderia por em paralelo, o ato lingüístico, se posso chamá-lo assim, tem a característica [de ser] o menos refletido, o menos premeditado e, ao mesmo tempo, o mais impessoal de todos (SAUSSURE, 2004, p. 132).

Mais do que mera convenção histórica, o sistema da língua impõe ao sujeito a submissão a um estado de interdependência, de forma que é só nos compromissos aceitos pelo espírito, em 
cada estado de língua, que os símbolos são efetivamente aceitos e a linguagem efetivamente ganha vida. Como que por um pacto, é na aceitação e no reconhecimento de uso, em cada funcionamento da língua, que ela é materialmente situada numa temporalidade pela comunidade falante e sua subjetividade. Em um ciclo contínuo, o "discurso se conjuga sempre sobre um discurso prévio, ao qual ele atribui o papel de matéria prima” (PÊCHEUX, 2019, p. 33-34), de forma que a Ideologia e o inconsciente estão sempre presentes, são assim partes constitutivas de cada estado de língua.

\section{POR UM ESFORÇO DE FECHAMENTO}

Explicamos estado de língua e efeito metafórico. Abordamos o processo pelo qual dois termos $x$ e $y$ quaisquer são submetidos ao teste das necessidades irremediáveis - posição funcional semelhante e condição de proximidade paradigmática - para que exista interpretação semântica idêntica entre eles, e dialogamos extensamente com as relações em presença (sintagmáticas) e em paralelie (associativas). Em seguida, explicamos os compromissos do espírito e seu papel na evolução da língua por meio das operações de analogia, tudo isso pautados nas relações extra sujeito constituintes dos sentidos.

Mediados pela teoria do discurso e seus meandros, propomos, neste gesto de leitura, explicitar que é somente com a estabilidade do estado de língua, como teorizada por Saussure, que podem ocorrer tanto as substituições contextuais do efeito metafórico quanto a atuação do espírito na própria evolução da língua. Assim, o processo de produção dos discursos possui conexão direta sempre com uma sincronia determinada, em relação que julgamos ser de dependência. Pois é nessa sincronia que "as propriedades gerais do signo podem ser consideradas" (SAUSSURE, 1975, p. 117) e na qual o analista pode se colocar "diante do objeto complexo que é a linguagem, para fazer seu estudo", abordando "necessariamente esse objeto por tal ou tal lado, que jamais será toda a linguagem” (SAUSSURE, 2004, p. 24).

O analista de discurso não é autorizado pela teoria pecheutiana da AAD-69 a reteorizar nem assimilar partes da linguística saussuriana e seu objeto, mas cabe a ele, em sua prática, operar com o todo do sistema da língua e condicionar uma perspectiva desse sistema a certa estabilidade para se ter o discurso fixado em sua base material. Dito isso, é impreterível que as prescrições teóricas concernentes tanto às condições de produção quanto ao sistema da língua sejam ambas obedecidas em sua integralidade pelo analista, pois somente dessa forma é que o tecido de elementos solidários se estrutura e permite que seja possível formular questões discursivas acerca do efeito metafórico e da evolução da língua. Dessa maneira, encaminhamo-nos a um efeito de fechamento dessa discussão.

No constructo montado por meio deste gesto de leitura mediado, evidenciamos que os processos inerentes ao efeito metafórico tensionam a relativa estabilidade do sistema da língua numa sincronia especificada. Na teoria do discurso, é inconcebível considerar a construção, a transformação, os esquemas de valor e as possibilidades de encadeamento semântico dos termos e suas significações como fatos meramente linguísticos, pois seria ignorar a presença constituinte da Ideologia e do inconsciente.

Dessa forma, o diálogo com as fontes autográficas nos Escritos de Linguística Geral (2004) foi especialmente proveitoso, pois, assim, tornou-se possível notarmos contribuições que 
estreitam o laço entre a AD e a linguística saussuriana por uma via muito pouco ressaltada - os aspectos psicológicos, o dito espírito - os pontos de fuga mais próximos da fala, o ato individual do sujeito. Essa relevância é materialmente demarcada em várias instâncias nos escritos autográficos saussurianos, como bem explicitado na observação colocada entre parênteses por ele ao tratar de "forma":

chama-se forma uma figura vocal que é determinada para a consciência dos sujeitos falantes. (A segunda menção é, na realidade, supérflua, porque nada existe além do que existe para a consciência; então, se uma figura vocal é determinada, ela o é imediatamente) (SAUSSURE, 2004, p. 47, grifos do autor).

Como já debatemos no curso deste artigo, a $\mathrm{AD}$ não se presta a absorver características de suas bases epistemológicas, mas funciona pelas frestas e pontos de deriva dessas teorias. Michel Pêcheux, como leitor atento de Ferdinand de Saussure, entendia bem o escopo e a abrangência do deslocamento saussuriano constitutivo da linguística moderna. Entretanto, como analistas do discurso, não podemos imputar à Saussure o que ele não disse, tampouco projetarmos em Pêcheux o que ele não teve acesso durante sua vivência nos círculos acadêmicos, como é o caso dos Escritos de Linguística Geral (2004).

Pêcheux não visava, com a $A A D 69$, expandir a linguística, assim ele não a fragmenta, não a incorpora nem a reduz, mas a toma por inteiro como necessidade irremediável ao trabalho dos analistas do discurso. No caso específico, é parcialmente se aproveitando dos objetos de não-estudo, das descontinuidades e dos espaços vazios definidos na linguística saussuriana pelo CLG, a vulgata, que ele monta o panorama epistemológico para delinear o objeto da AD, o discurso. Essa conformação epistemológica era necessária para que fosse possível a criação de uma teoria que propusesse investigar, com base na língua, os processos de produção discursiva pelos quais os efeitos de sentido tanto se estabelecem quanto deslizam.

Fundado um campo no qual se tem como etapa primeira se debruçar sobre o sistema da língua para sua prática, toma-se que "para cada ordem, com efeito, sente-se a necessidade de determinar o objeto; e, para determiná-lo, recorre-se, maquinalmente, a uma segunda ordem” (SAUSSURE, 2004, p. 27). O discurso como objeto só pode ser mais bem determinado e compreendido quando o pesquisador, em sua prática-teórica, toma nota das minúcias dessas outras ordens que estão ali colocadas no campo, sendo elas tomadas como base epistemológica ou então como pontos de inflexão. Assim, é relevante traçar diálogos com esses diferentes “Saussures” quando buscamos nos inserir neste esforço de renovação do interesse pela AAD69 frente à comunidade acadêmica.

\section{REFERÊNCIAS}

ARRIVÉ, Michel. Em busca de Ferdinand de Saussure. Tradução de Marcos Marcionilo. São Paulo: Parábola, 2010 [2007]. 253 p.

GADET, Françoise et al. Apresentação da conjuntura em linguística, em psicanálise e em informática aplicada aos estudos dos textos na França, em 1969. In: GADET, Françoise; HAK, Tony. (Org.). Por uma análise automática do discurso: uma introdução à obra de Michel 
Pêcheux. Campinas, SP: Editora da Unicamp, 2014 [1990]. 5. ed. 320 p. Tradução de Bethania S. Mariani et al.

KUHN, Thomas S. A estrutura das revoluções científicas. 12. ed. Tradução de Beatriz Vianna Boeira e Nelson Boeira. São Paulo: Perspectiva, 2013 [1962]. 323 p.

PÊCHEUX, Michel. Análise automática do discurso. Tradução de Eni Pulccinelli Orlandi e Greciely Costa. Campinas: Pontes, 2019 [1969].

PÊCHEUX, Michel; FUCHS, Catherine. A propósito da análise automática do discurso: atualização e perspectivas. In: GADET, Françoise; HAK, Tony. (Org.). Por uma análise automática do discurso: uma introdução à obra de Michel Pêcheux. Tradução de Bethania S. Mariani et al. 5. ed. Campinas, SP: Editora da Unicamp, 2014 [1990]. 5. ed. 320 p.

SAUSSURE, Ferdinand. Curso de linguística geral. Organizado por Charles Bally e Albert Sechehaye com a colaboração de Albert Riedlinger. São Paulo: Cultrix, 1975 [1916], 279 p. 7. ed. Tradução de Antônio Chelini, José Paulo Paes e Izidoro Blikstein.

SAUSSURE, Ferdinand. Escritos de linguística geral. Tradução de Carlos Augusto Leuba Salum e Ana Lucia Franco. São Paulo: Cultrix, 2004 [2002]. Organização de Simon Bouquet e Rudolf Engler.

Recebido em: jun. 2020.

Aceito em: set. 2020. 